\title{
Calibration and Validation of an Experimental Setup for the Measurement of the Cylindrical Body Shapes and Curvatures of the Objects and Subjects through the Techniques of Rasterstereography
}

\author{
MAJEED AHMED KHAN*, AND SYED ANWER ALI ZAIDI* \\ RECEIVED ON 15.05.2017 ACCEPTED ON 25.05.2018
}

\begin{abstract}
The intent of study is to establish a criterion for the experimental setup of rasterstereography, one that is more efficient, simple, accurate and precise to examine and analyse the curvature of the object or the subject. Firstly, the setup is needed to be calibrated and for this purpose we considered a reference plane, eleven cylinders of different diameter ranging from $30-119 \mathrm{~mm}$ were used for calibration of curvature maps of cylinders and cylindrical objects through the regression line. Further this model was tested on subjects and for that we reckoned cylindrical body parts of boys and a total of 30 college students were involved as subjects in this process. The body parts to be measured had curvature like cylinders of different diameters ranging from $42-120 \mathrm{~mm}$. The distortion of raster grid was observed, quantified and recorded with the help of different tools and results were established. The regression line was obtained between the measured $(x)$ and computed $(y)$. The standard error of the cylindrical object was 0.04 and that of cylindrical body parts of subjects was 0.0407 . This technique was validated through the coefficient of correlation for objects and subjects which was found to be $\mathbf{0 . 9 9 9 8 2}$ and 0.999141 respectively. Accuracy and Precision were also calculated for this model, which were $99.60 \%$ accurate and $99.49 \%$ precise. Curvature maps were found more than $\mathbf{9 9 \%}$. This technique is inexpensive, reliable, reproducible and may be installed easily in hospitals to examine appraise body shape, composition and deformities of young men.
\end{abstract}

Key Words: Surface Topography, Photogrammetry, Curvature, Rasterstereography, Calibration, Validation

\section{INTRODUCTION}

I

$\mathrm{t}$ is very important for the blessing of the whole humanity to develop more efficient new methods to determine the surface type and shapes. There were different types of methods used for range images, one segmentation method for detecting various surfaces yields three types of surfaces, whereas other methods consider eight basic types of surfaces based on signs of mean and Gaussian curvatures. Surface-shape-detection

Authors E-Mail: (majeedahmed0786@gmail.com, anwerzaidi1958@yahoo.com)

* Department of Mathematics, University of Karachi, Karachi, Pakistan.

This is an open access article published by Mehran University Research Journal of Engineering and Technology, Jamshoro under the CC by 4.0 International License. 
methods can be applied to many fields, including medical sciences. For example, when physicians start to diagnoses the different types of body shapes deformities by using expensive equipment such as X-Rays and CT scans, etc. These techniques involve the risk of radiation. We need an inexpensive, fast, automated technique to filter out the suspected cases having different types of body shapes deformities. Rasterstereography is an inexpensive, simple, noninvasive, noncontact optical-imaging technique, which provides three-dimensional curvature maps of the object or the subject under study. It is being used in some countries for the diagnosis, the documentation, the follow-up and the quantification of different types of body shapes deformities, when the raster grid projected on the body. It is distorted. The study of this distortion provides information about topographical properties of the surface under study (Frobin and Hierholzer [1]). Frobin and Hierholzer [2] used rasterstereography for the measurement of body surfaces. Hierholzer and Schier [3] applied rasterstereography for the measurement of chest-wall deformities. Arffa et. al. [4] measured different body curvatures through rasterstereography. Naufal et. al. [5] classified normal corneas using rasterstereography. Hierholzer [6] calibrated video-rasterstereographic system. Drerup and Hierholzer [7] measured back-shape curvature using rasterstereography. Zubairi and Kamal [8] developed a methodology for spinal- deformity detection using rasterstereography. Zubairi [9] performed another work on surface shape recognition and applications by using computer aided rasterstereography. Drerup et. al. [10] developed a new method for biomechanical analysis of skeletal geometry using functional rasterstereographic images. Guarnieri, and Guarnieri [11] investigated accuracy of rasterstereography versus radiography in idiopathic scoliosis after anterior and posterior correction and fusion. Hackenberget. al. [12] worked on the accuracy of rasterstereography versus radiography in idiopathic scoliosis. Hackenberg et. al. [13] worked on back shape analysis by rasterstereography. Schroeder et. al. [14], worked on back shape reconstruction by Video raster stereography. Yoon et. al. [15] worked on Reliability and Validity of Rasterstereography measurement for spinal alignment in healthy subjects. Anne et. al. [16] worked on Validity and Reliability of spine Rasterstereography in Patients.

The remarkable feature of this technique is that it does not need the specific arrangement of the apparatus to obtain meaningful raster. All the setup of this technique is portable and handy. It can easily be transported and can be set up elsewhere and so it is reproducible. Results were not altered with the change in position of apparatus. It is inexpensive as the requirements for the apparatus only

consist of OHP (Over Head Projector), Raster Grid, Digital camera, a computer and the approximate cost of all these things is PKR. 50,000/-. Only one person is required to run the setup and cost to examine one person is less than PKR. 50/-.

Accuracy and precision of this technique is relatively better than the other techniques and that is why it is more reliable. This technique measures and examines the minimum abnormalities on the surface of the subjects which can be easily ignored by physicians and doctors during examinations and can timely identify any structural anomalies and by doing serial measurements by this technique appropriate treatment can be commenced and so adverse outcomes can be avoided and thereby making this technique efficient and effective. This technique has all these characteristics. For the accuracy of the results we need to calibrate and validate it by using some statistical tools. 


\subsection{Technique of Rasterstereography}

If a raster grid is projected onto a curved body surfaces, the raster lines shows distortion, which is 3D (ThreeDimensional) in shapes. This distortion can be calculated by different methods. This technique understood most clearly by a comparison with conventional stereophotography. In the case of rasterstereography, one camera is replaced by a OHP from the setup of stereophotography. So the basic setup consists of a raster grid, a camera, a OHP, computer with a software to calculate the curvature.

There are two basic types of invariants, local and global ones. Global invariants are quantities such as distances, angles, areas, and volumes and the principal local invariant of a surface is its curvature.

Both types of invariants can be calculated from rasterstereography. Through calculus. These invariants may be represented by the two extreme curvatures in two orthogonal directions, the principal curvatures of surface points can be divided into four classes.

(a) At a planar point the surface is a plane with no curvature at all.

(b) At a parabolic point the surface is a cylinder with one principal curvature equal to zero.

(c) At an elliptical point both principal curvatures are finite and of equal sign.

(d) At a hyperbolic point the principal curvatures are of opposite sign.

The convexity or concavity of the surface is represented by the sign of principal curvatures $\kappa_{1}$ and $\kappa_{2}$
The mean curvature is given by:

$H=\frac{\kappa_{1}+\kappa_{2}}{2}$

and the Gaussian curvature by:

$$
G=\sqrt{\kappa_{1} \kappa_{2}}
$$

Instead of the principal curvatures themselves, these quantities can be used equally well for an invariant shape analysis.

\section{MATERIALS AND METHODS}

\subsection{Statement of the Problem}

Researchers used this technique in some fields, but most of them applied in clinical sides. Specially this technique was used just to analyse the back shape, scoliosis, orthodontics and surface shapes of other body parts. It is surprising that after more than thirty years the benefits of rasterstereography are very far from the reach of humanity. This factor could be minimized by the new setup of rasterstereography.

\section{$2.2 \quad$ Setup}

Objects of various sizes were placed on reference surface. First of all, objects were aligned with the help of reference surface and spirit level. A raster grid placed on overhead projector and it was $1500 \mathrm{~mm}$ away from object. A traveling telescope and camera vertically aligned in the same line, which were $1500 \mathrm{~mm}$ from the object and $100 \mathrm{~mm}$ from the Overhead Projector. Experimental setup of Rasterstereography shown in Fig. 1. 


\subsection{Method}

A raster grid was projected on the object or Subject which was placed and aligned on reference plane. The periodic spacing on the reference surface (flat surface) is $\mathrm{S}$ and $\mathrm{X}$ is the periodic spacing on the curved surface(measured) and the distortions of the curved Object or Subject recorded with the help of traveling telescope and camera simultaneously and it is $d$ (for the calculation of radius of curvature). A software was used for the calculation of radius of curvature.

\subsection{Calculations}

After measurements of periodic spacing of the plane surface " $s$ " and periodic spacing of curved surface " $d$ " for cylinders and Cylindrical body parts of the subjects, horizontal curvature $\left(\mathrm{k}_{1}\right)$, and vertical curvature $\left(\mathrm{k}_{2}\right)$, and radius of curvature $(\mathrm{y})$ were calculated.

Radius of curvature ' $y$ ' is given by:

$y=\frac{1}{\kappa}(\mathrm{mm})$
Whereк is the curvature which is given by:

$$
K=\frac{1}{s} \sqrt{\left|6\left(1-\frac{d}{s}\right)\right|}\left(m m^{-1}\right)
$$

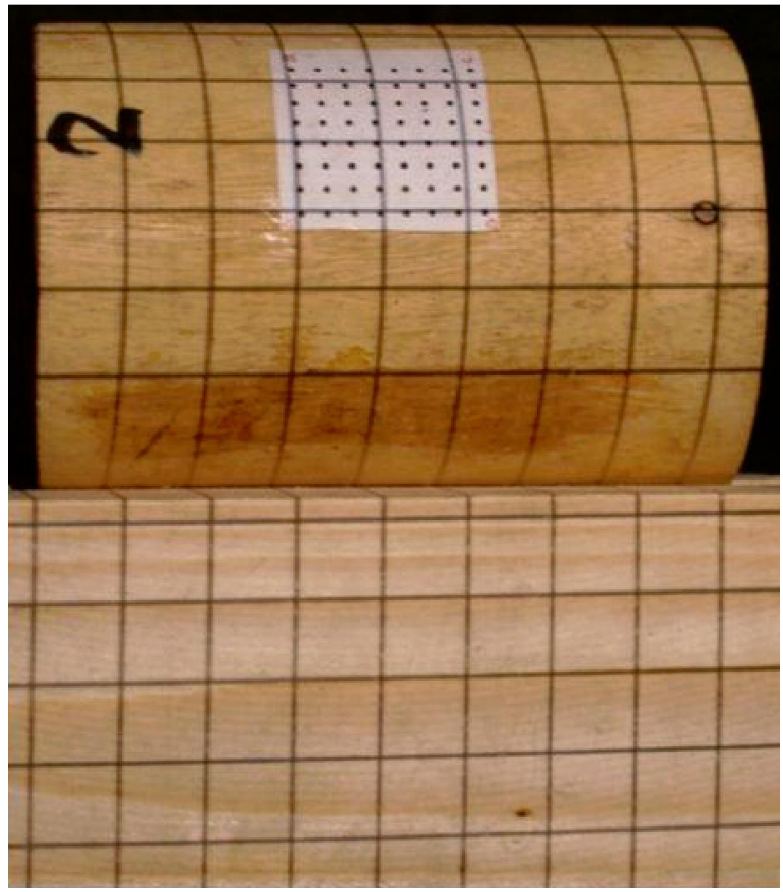

FIG. 2. CYLINDER AND PLANE SURFACE

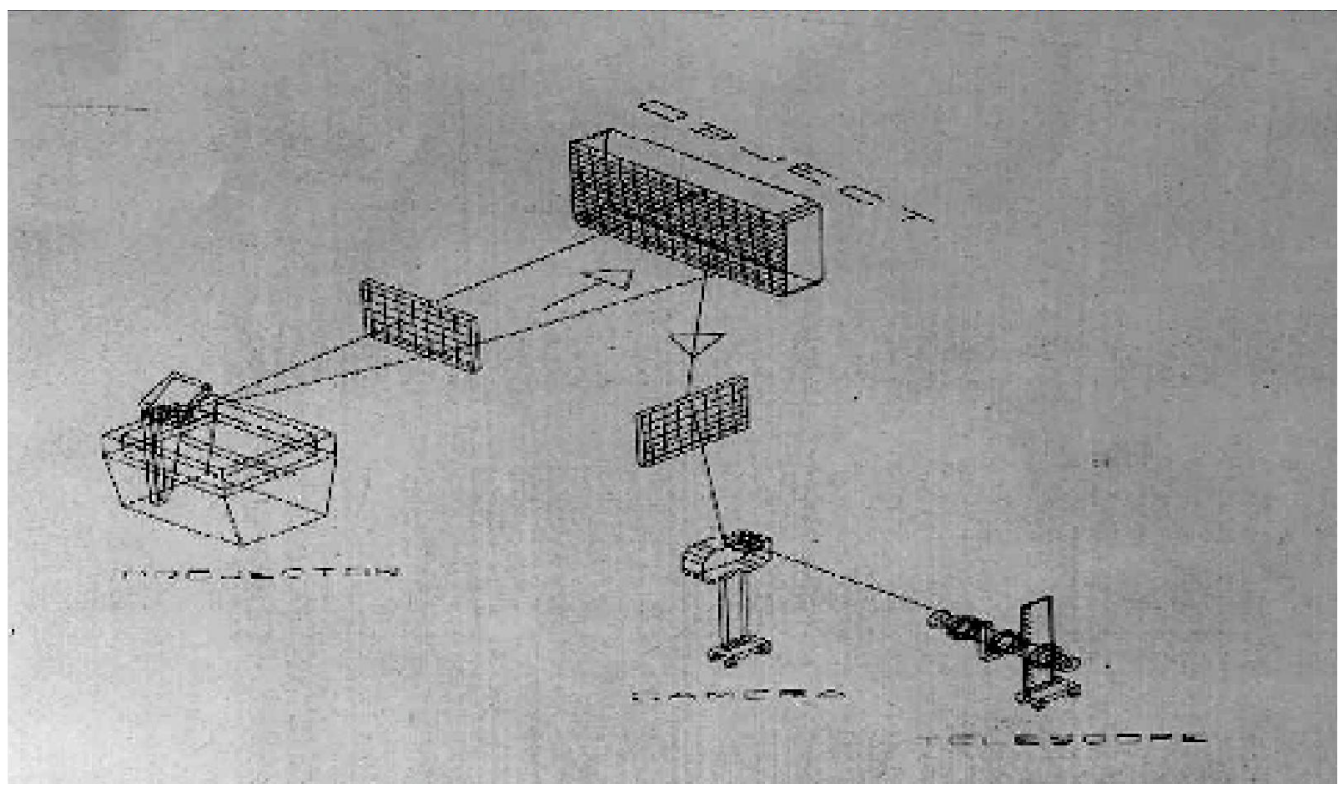

FIG. 1. SETUP OF RASTER STEREOGRAPHY 


\subsection{Observation for Cylinders}

Eleven cylinders of different diameters and a reference plane were considered to measure the periodic spacing of the plane surface (S) and periodic spacing of curved surface (d) for the calculation of curvature and radius of curvature.

When the raster grid projected on cylinders and plane surface for the calculation of curvature. The Horizontal curvature, $\mathrm{k}_{1}=0$ and Vertical Curvatures of cylinders as shown in Table 1.
Graphical and Bar Chart representation for radii of eleven cylinders between measured and computed values as shown in Figs. 3-4.

\subsection{Observation for Cylindrical Body Parts of the Subjects}

When a raster grid projected on cylindrical body parts of the subjects the periodic spacing of the plane surface (s) and the periodic spacing of the curved surface (d) were measured for the calculation of Curvatures and radius of Curvatures.The Horizontal Curvature $\left(\mathrm{k}_{1}\right)$ is zero

TABLE 1. CALCULATIONS OF VERTICAL CURVATURE OF CYLINDERS

\begin{tabular}{|c|c|c|c|c|}
\hline Cylinder No. & $\begin{array}{c}\text { Radius }(\mathrm{x}) \\
(\mathrm{mm})\end{array}$ & $\begin{array}{c}\mathrm{D} \\
(\mathrm{mm})\end{array}$ & $\begin{array}{c}\mathrm{K}_{2} \\
(\mathrm{~mm}-1)\end{array}$ & $\begin{array}{c}y=1 / \mathrm{k}_{2} \\
(\mathrm{~mm})\end{array}$ \\
\hline 1. & 59.50 & 16.00 & 0.0168 & 59.52 \\
\hline 2. & 54.00 & 15.96 & 0.0184 & 54.33 \\
\hline 3. & 44.50 & 15.84 & 0.0225 & 44.36 \\
\hline 4. & 38.00 & 15.71 & 0.0263 & 38.02 \\
\hline 5. & 35.50 & 15.61 & 0.0279 & 35.89 \\
\hline 6. & 37.00 & 15.69 & 0.0268 & 37.27 \\
\hline 7. & 32.50 & 15.53 & 0.0307 & 32.52 \\
\hline 8. & 32.00 & 15.51 & 0.0312 & 32.04 \\
\hline 9. & 25.00 & 15.10 & 0.0394 & 25.38 \\
\hline 10. & 19.50 & 14.35 & 0.0510 & 19.57 \\
\hline 11. & 15.00 & 13.10 & 0.0661 & 15.11 \\
\hline
\end{tabular}

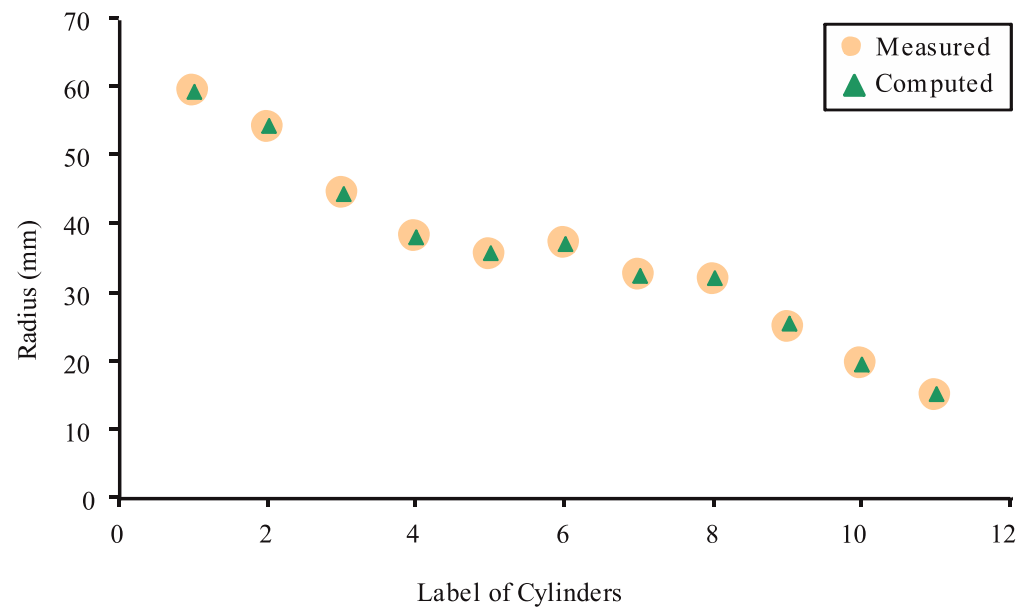

FIG. 3. GRAPH FOR RADII OF CYLINDERS BETWEEN MEASURED AND COMPUTED 
andVertical curvature for the body part of different subjects $\left(\mathrm{k}_{2}\right)$ as shown in Fig. 5 and Table 2.

Graph between the Actual and Theoretical Radii for the cylindrical body parts of subjects which shows the results were more than $99 \%$ correct that shown in Figs. 6-7.

\subsection{Regression Line}

A line was fitted between the measured (x) and computed radii (Y) of curvature of various objects and subjects (Tables 3-4 and Figs. 8-9)

\subsection{Accuracy and Precision for Cylinderical Subjects}

Accuracy and Precision of measurement of vertical curvature were calculated by taking five points on the surface of cylindrical body parts of the subjects as shown in Tables 5-7 and Figs. 10-11.

The reference value ' $R$ ' in the data is found to be as $\mathrm{R}=35.7398 \mathrm{~mm}$, which is close to actualvalue $\mathrm{x}=35.81$, $\mathrm{x}=35.5409, \mathrm{D}=0.1821, \mathrm{D}_{\mathrm{R}}=0.1434$.

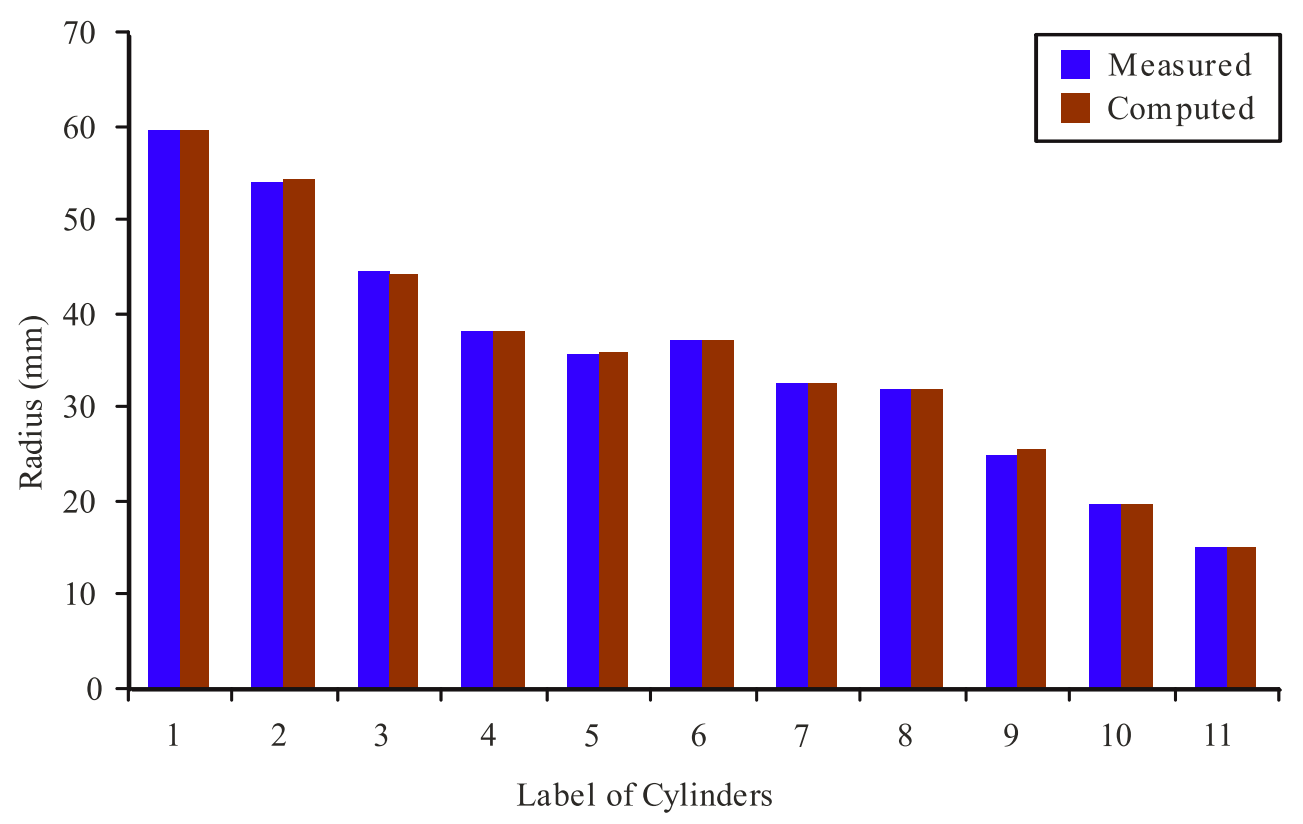

FIG. 4. BAR CHART FOR RADII OF CYLINDERS BETWEEN MEASURED AND COMPUTED
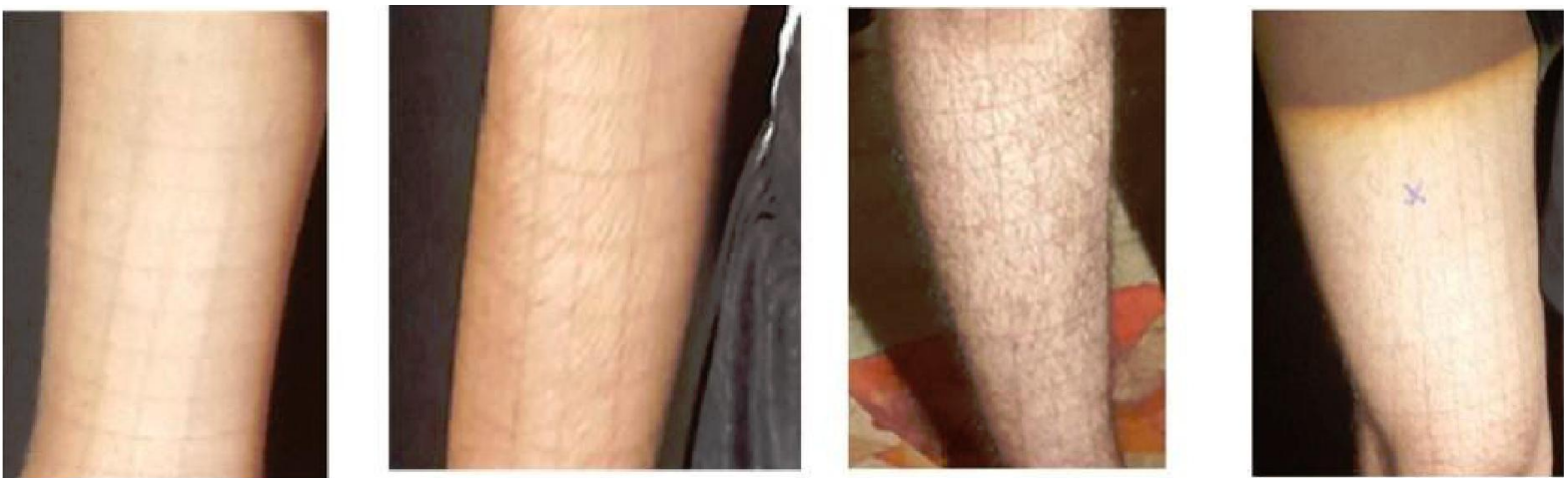

FIG. 5. CYLINDRICAL BODY PARTS OF THE SUBJECT

Mehran University Research Journal of Engineering \& Technology, Volume 38, No. 1, January, 2019 [p-ISSN: 0254-7821, e-ISSN: 2413-7219] 
Calibration and Validation of an Experimental Setup for the Measurement of the Cylindrical Body Shapes and Curvatures of the Objects and Subjects through the Techniques of Rasterstereography

TABLE 2. STATISTICAL ANALYSIS FOR VERTICAL CURVATURE FOR THE BODY PARTS

\begin{tabular}{|c|c|c|c|c|c|c|c|c|c|}
\hline $\begin{array}{c}\text { Cylinder of } \\
\text { Subjects No. }\end{array}$ & $\begin{array}{c}\mathrm{d} \\
(\mathrm{mm}) \\
\end{array}$ & $\begin{array}{c}\mathrm{k}_{2} \\
\left(\mathrm{~mm}^{-1}\right) \\
\end{array}$ & $\begin{array}{c}\mathrm{X} \\
(\mathrm{mm}) \\
\end{array}$ & $\begin{array}{c}y=1 / k_{2} \\
(\mathrm{~mm})\end{array}$ & $\begin{array}{c}\mathrm{xy} \\
\left(\mathrm{mm}^{2}\right) \\
\end{array}$ & $\begin{array}{c}\mathrm{X}^{2} \\
\left(\mathrm{~mm}^{2}\right) \\
\end{array}$ & $\begin{array}{c}\mathrm{y}^{2} \\
\left(\mathrm{~mm}^{2}\right) \\
\end{array}$ & $\hat{y}(\mathrm{~mm})$ & $\begin{array}{c}\mathrm{e}^{2}=(\mathrm{y}-\hat{\mathrm{y}})^{2} \\
\left(\mathrm{~mm}^{2}\right)\end{array}$ \\
\hline 1. & 15.880 & 0.021 & 46.95 & 47.619 & 2235.714286 & 2204.3025 & 2267.574 & 47.609 & 0.000 \\
\hline 2. & 15.820 & 0.023 & 42.97 & 43.478 & 1868.26087 & 1846.4209 & 1890.359 & 43.271 & 0.043 \\
\hline 3. & 15.800 & 0.024 & 42.18 & 41.667 & 1757.500 & 1779.1524 & 1736.111 & 41.612 & 0.003 \\
\hline 4. & 15.650 & 0.028 & 35.81 & 35.714 & 1278.928571 & 1282.3561 & 1275.510 & 35.884 & 0.029 \\
\hline 5. & 15.230 & 0.037 & 27.06 & 27.027 & 731.351 & 732.244 & 730.460 & 27.017 & 0.000 \\
\hline 6. & 15.980 & 0.018 & 56.50 & 55.556 & 3138.888889 & 3192.250 & 3086.420 & 55.512 & 0.002 \\
\hline 7. & 15.736 & 0.026 & 38.98 & 38.462 & 1499.230769 & 1519.440 & 1479.290 & 38.412 & 0.002 \\
\hline 8. & 15.630 & 0.028 & 35.01 & 35.714 & 1250.357143 & 1225.700 & 1275.510 & 35.694 & 0.000 \\
\hline 9. & 15.710 & 0.026 & 38.20 & 38.462 & 1469.230769 & 1459.240 & 1479.290 & 38.232 & 0.053 \\
\hline 10. & 14.960 & 0.042 & 23.87 & 23.810 & 568.333 & 569.777 & 566.893 & 23.905 & 0.009 \\
\hline 11. & 15.970 & 0.018 & 55.70 & 55.556 & 3094.444444 & 3102.490 & 3086.420 & 55.511 & 0.002 \\
\hline 12. & 15.890 & 0.021 & 47.75 & 47.619 & 2273.810 & 2280.0625 & 2267.574 & 47.815 & 0.038 \\
\hline 13. & 15.970 & 0.019 & 53.32 & 52.632 & 2806.315789 & 2843.0224 & 2770.083 & 52.581 & 0.003 \\
\hline 14. & 15.990 & 0.017 & 58.09 & 58.824 & 3417.058824 & 3374.4481 & 3460.208 & 58.702 & 0.015 \\
\hline 15. & 15.920 & 0.020 & 50.13 & 50.000 & 2506.500 & 2513.0169 & 2500.000 & 50.306 & 0.094 \\
\hline 16. & 15.940 & 0.019 & 52.52 & 52.632 & 2764.210526 & 2758.350 & 2770.083 & 52.432 & 0.040 \\
\hline 17. & 15.60 & 0.029 & 34.22 & 34.483 & 1180.000 & 1171.0084 & 1189.061 & 34.352 & 0.017 \\
\hline 18. & 15.460 & 0.032 & 30.87 & 31.250 & 964.688 & 952.957 & 976.563 & 31.198 & 0.003 \\
\hline 19. & 15.040 & 0.040 & 24.67 & 25.000 & 616.750 & 608.609 & 625.000 & 24.701 & 0.089 \\
\hline 20. & 15.960 & 0.018 & 54.11 & 55.556 & 3006.111111 & 2927.8921 & 3086.420 & 55.423 & 0.018 \\
\hline 21. & 15.910 & 0.020 & 49.34 & 50.000 & 2467.000 & 2434.4356 & 2500.000 & 50 & 0.011 \\
\hline 22. & 15.670 & 0.027 & 36.61 & 37.037 & 1355.925926 & 1340.2921 & 1371.742 & 36.985 & 0.003 \\
\hline 23. & 15.530 & 0.031 & 32.63 & 32.258 & 1052.580645 & 1064.7169 & 1040.583 & 32.512 & 0.064 \\
\hline 24. & 15.110 & 0.039 & 25.46 & 25.641 & 652.821 & 648.212 & 657.462 & 25.471 & 0.029 \\
\hline 25. & 15.750 & 0.025 & 39.79 & 40.000 & 1591.600 & 1583.2441 & 1600.000 & 39.671 & 0.108 \\
\hline 26. & 15.600 & 0.029 & 34.42 & 34.483 & 1186.896552 & 1184.7364 & 1189.061 & 34.351 & 0.017 \\
\hline 27. & 15.500 & 0.031 & 31.83 & 32.258 & 1026.774194 & 1013.1489 & 1040.583 & 31.813 & 0.198 \\
\hline 28. & 15.380 & 0.034 & 29.44 & 29.412 & 865.882 & 866.714 & 865.052 & 29.371 & 0.002 \\
\hline 29. & 15.230 & 0.037 & 27.06 & 27.027 & 731.351 & 732.244 & 730.460 & 27.012 & 0.000 \\
\hline 30. & 14.670 & 0.046 & 21.49 & 21.739 & 467.174 & 461.820 & 472.590 & 21.510 & 0.053 \\
\hline 31. & 15.930 & 0.020 & 50.93 & 50.000 & 2546.500 & 2593.8649 & 2500.000 & 49.930 & 0.005 \\
\hline 32. & 15.840 & 0.023 & 44.56 & 43.478 & 1937.391304 & 1985.5936 & 1890.359 & 43.681 & 0.041 \\
\hline 33. & 15.870 & 0.022 & 46.15 & 45.455 & 2097.727273 & 2129.8225 & 2066.116 & 45.219 & 0.055 \\
\hline 34. & 15.470 & 0.032 & 31.04 & 31.250 & 970.000 & 963.482 & 976.563 & 31.149 & 0.010 \\
\hline 35. & 15.796 & 0.024 & 41.38 & 41.667 & 1724.166667 & 1712.3044 & 1736.111 & 41.563 & 0.011 \\
\hline 36. & 15.676 & 0.027 & 36.61 & 37.037 & 1355.925926 & 1340.2921 & 1371.742 & 36.894 & 0.020 \\
\hline 37. & 15.346 & 0.035 & 28.65 & 28.571 & 818.571 & 820.823 & 816.327 & 28.493 & 0.006 \\
\hline 38. & 15.710 & 0.026 & 38.20 & 38.462 & 1469.230769 & 1459.240 & 1479.290 & 38.021 & 0.194 \\
\hline 39. & 15.596 & 0.029 & 34.22 & 34.483 & 1180.000 & 1171.0084 & 1189.061 & 34.071 & 0.170 \\
\hline 40. & 14.870 & 0.043 & 23.08 & 23.256 & 536.744 & 532.686 & 540.833 & 23.051 & 0.042 \\
\hline 41. & 15.770 & 0.025 & 40.58 & 40.000 & 1623.200 & 1646.7364 & 1600.000 & 40.520 & 0.270 \\
\hline 42. & 15.240 & 0.037 & 27.07 & 27.027 & 731.622 & 732.785 & 730.460 & 27.021 & 0.000 \\
\hline 43. & 16.00 & 0.017 & 58.89 & 58.824 & 3464.117647 & 3468.0321 & 3460.208 & 58.731 & 0.009 \\
\hline 44. & 15.570 & 0.030 & 33.42 & 33.333 & 1114.000 & 1116.8964 & 1111.111 & 33.525 & 0.037 \\
\hline 45. & 15.80 & 0.021 & 46.95 & 47.619 & 2235.714 & 2204.3025 & 2267.574 & 47.583 & 0.001 \\
\hline 46. & 15.750 & 0.025 & 39.79 & 40.000 & 1591.600 & 1583.2441 & 1600.000 & 39.672 & 0.108 \\
\hline 47. & 15.870 & 0.022 & 46.93 & 45.455 & 2133.182 & 2202.4249 & 2066.116 & 45.129 & 0.106 \\
\hline 48. & 15.970 & 0.018 & 55.70 & 55.556 & 3094.444 & 3102.490 & 3086.420 & 55.510 & 0.002 \\
\hline 49. & 15.990 & 0.017 & 57.30 & 58.824 & 3370.588 & 3283.290 & 3460.208 & 58.792 & 0.001 \\
\hline 50. & 16.010 & 0.016 & 60.48 & 62.500 & 3780.000 & 3657.830 & 3906.250 & 62.437 & 0.004 \\
\hline$\Sigma$ & & & 2018.91 & 2023.707 & 87600.415 & 87379.451 & 87832.111 & & 2.037 \\
\hline
\end{tabular}

Mehran University Research Journal of Engineering \& Technology, Volume 38, No. 1, January, 2019 [p-ISSN: 0254-7821, e-ISSN: 2413-7219] 


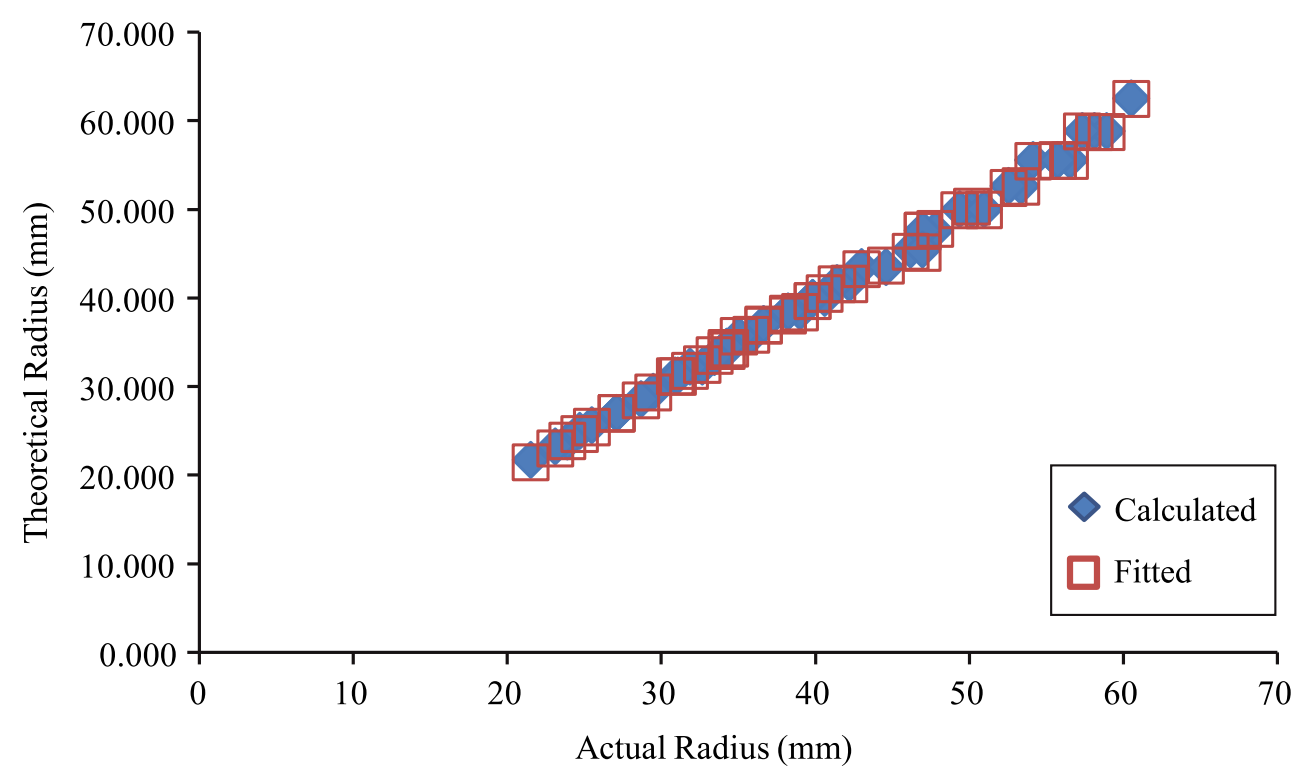

FIG. 6. GRAPH BETWEEN THE ACTUAL AND THEORETICAL RADII FOR THE CYLINDRICAL BODY PARTS OF SUBJECTS

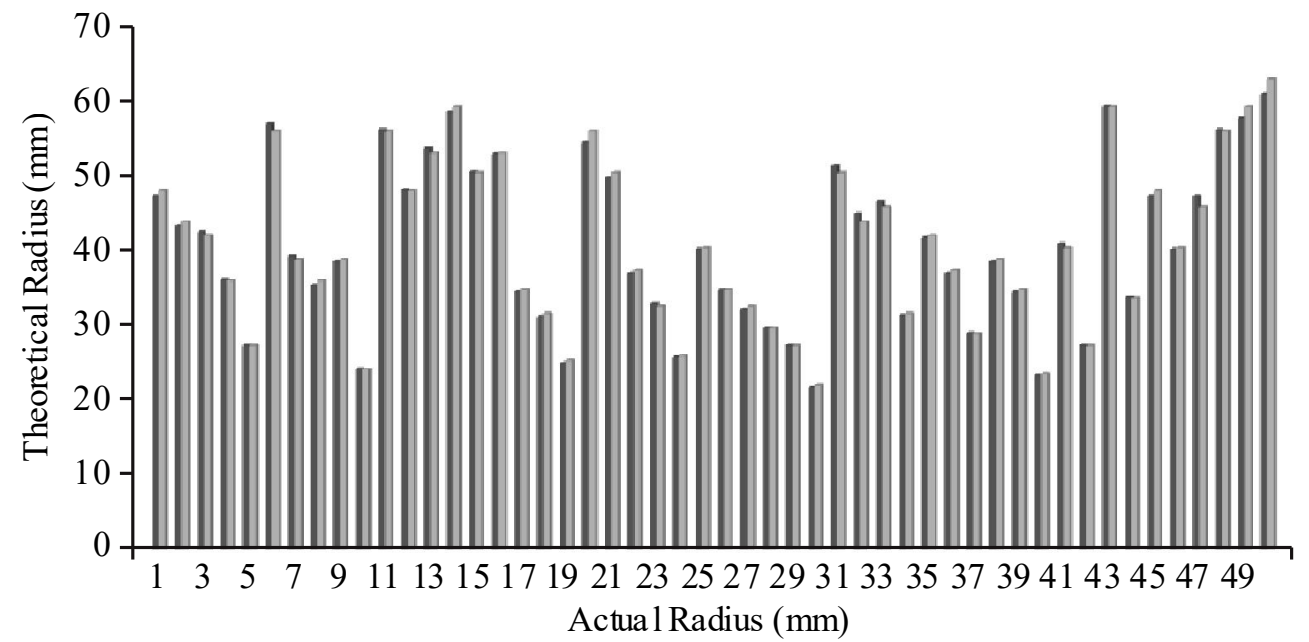

FIG. 7. COLUMN CHART BETWEEN ACTUAL AND THEORETICAL RADII FOR CYLINDERS OF THE SUBJECTS

TABLE 3. REGRESSION LINE

\begin{tabular}{|c|c|c|}
\hline No. & Curvature & Regression Line \\
\hline 1. & Vertical Curvature of Object & $\mathrm{Y}=0.9327+0.9993 \mathrm{x}$ \\
\hline 2. & Vertical Curvature of Subject & $\mathrm{Y}=1.0048+0.9683 \mathrm{x}$ \\
\hline
\end{tabular}

TABLE 4. COEFFICIENT OF CORRELATION AND STANDARD ERROR FOR CYLINDERS AND SUBJECTS

\begin{tabular}{|c|c|c|c|}
\hline No. & Curvature of Objects & Coefficient of Correlation & Standard Error \\
\hline 1. & $\begin{array}{c}\text { Vertical Curvature of different cylindrical } \\
\text { objects }\end{array}$ & 0.99982 & 0.04 \\
\hline 2. & $\begin{array}{c}\text { Vertical Curvature of different cylindrical } \\
\text { subjects }\end{array}$ & 0.98498 & 0.0231 \\
\hline
\end{tabular}

Mehran University Research Journal of Engineering \& Technology, Volume 38, No. 1, January, 2019 [p-ISSN: 0254-7821, e-ISSN: 2413-7219] 


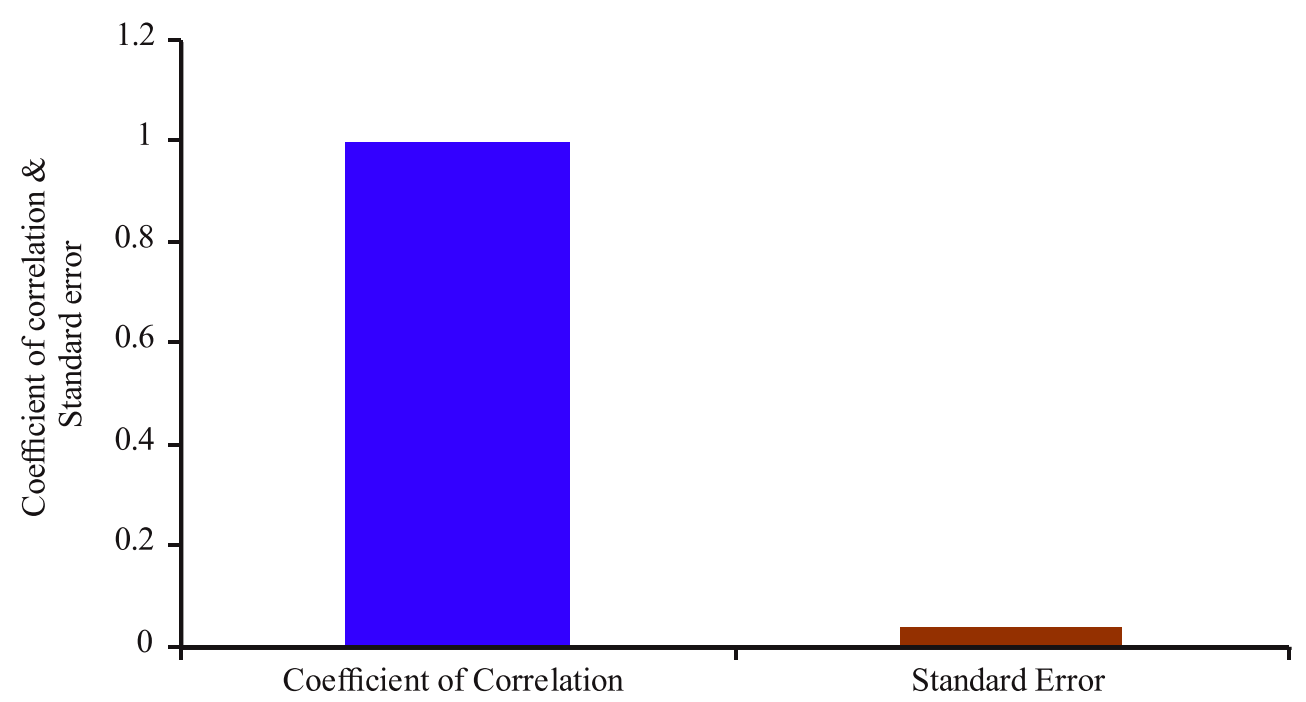

FIG. 8. BAR CHART OF COEFFICIENT OF CORRELATION AND STANDARD ERROR FOR OBJECTS

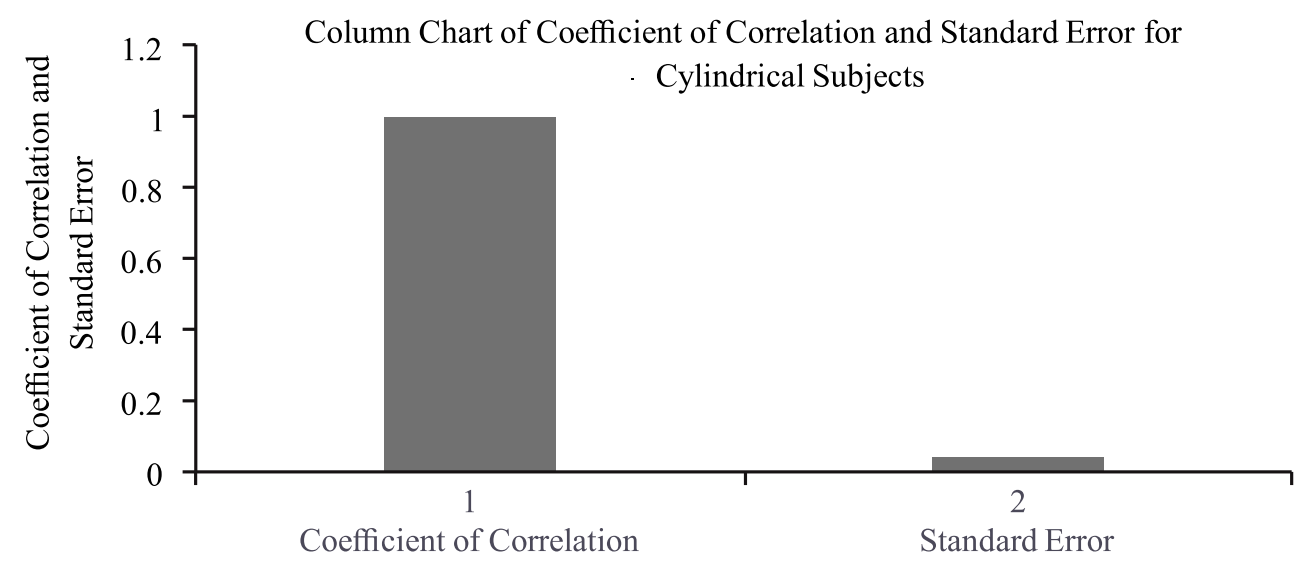

FIG. 9. BAR CHART OF COEFFICIENT OF CORRELATION AND STANDARD ERROR FOR SUBJECTS

TABLE 5. ACCURACY AND PRECISION FOR CYLINDERICAL SUBJECTS

\begin{tabular}{|c|c|c|c|c|c|}
\hline \multirow{2}{*}{ No. } & $\begin{array}{c}\mathrm{d} \\
(\mathrm{mm})\end{array}$ & $\begin{array}{c}\mathrm{K}_{2} \\
\left(\mathrm{~mm}^{-1}\right)\end{array}$ & $\begin{array}{c}\mathrm{x}_{1}=1 / \mathrm{K}_{2} \\
(\mathrm{~mm})\end{array}$ & $\begin{array}{c}\left|\mathrm{x}_{\mathrm{i}}-\mathrm{x}\right| \\
(\mathrm{mm})\end{array}$ & $\begin{array}{c}\left|\mathrm{x}_{\mathrm{i}}-\mathrm{R}\right| \\
(\mathrm{mm})\end{array}$ \\
\cline { 2 - 6 } & 15.650 & 0.02786 & 35.8937 & 0.3527 & 0.1539 \\
\hline 2. & 15.645 & 0.02798 & 35.7398 & 0.1989 & 0.0000 \\
\hline 3. & 15.645 & 0.02812 & 35.5618 & 0.0209 & 0.1780 \\
\hline 4. & 15.645 & 0.02805 & 35.6506 & 0.1097 & 0.0892 \\
\hline 5. & 15.645 & 0.02810 & 35.5872 & 0.0463 & 0.1526 \\
\hline
\end{tabular}

TABLE 6. ACCURACY AND PRECISION FOR CYLINDER

\begin{tabular}{|c|c|c|c|}
\hline No. & Curvature of Cylinder & Accuracy (\%) & Precision (\%) \\
\hline 1. & Vertical Curvature K? & 99.55 & 99.45 \\
\hline
\end{tabular}

Mehran University Research Journal of Engineering \& Technology, Volume 38, No. 1, January, 2019 [p-ISSN: 0254-7821, e-ISSN: 2413-7219] 


\subsection{Statistical Analysis}

For statistical analysis coefficient of correlation ' $r$ ' was calculated by:

$r=\sqrt{b_{x / y} b_{y / x}}$

where

$$
b_{x / y}=\frac{n \sum x y-\sum x \sum y}{n \sum x^{2}-\left(\sum x\right)^{2}}
$$

and

$b_{y / x}=\frac{n \sum x y-\sum x \sum y}{n \sum y^{2}-\left(\sum y\right)^{2}}$

TABLE 7. ACCURACY AND PRECISION FOR CYLINDRICAL SUBJECTS

\begin{tabular}{|c|c|c|}
\hline No. & Accuracy & Precision (\%) \\
\hline 1. & $99.60 \%$ & 99.49 \\
\hline
\end{tabular}

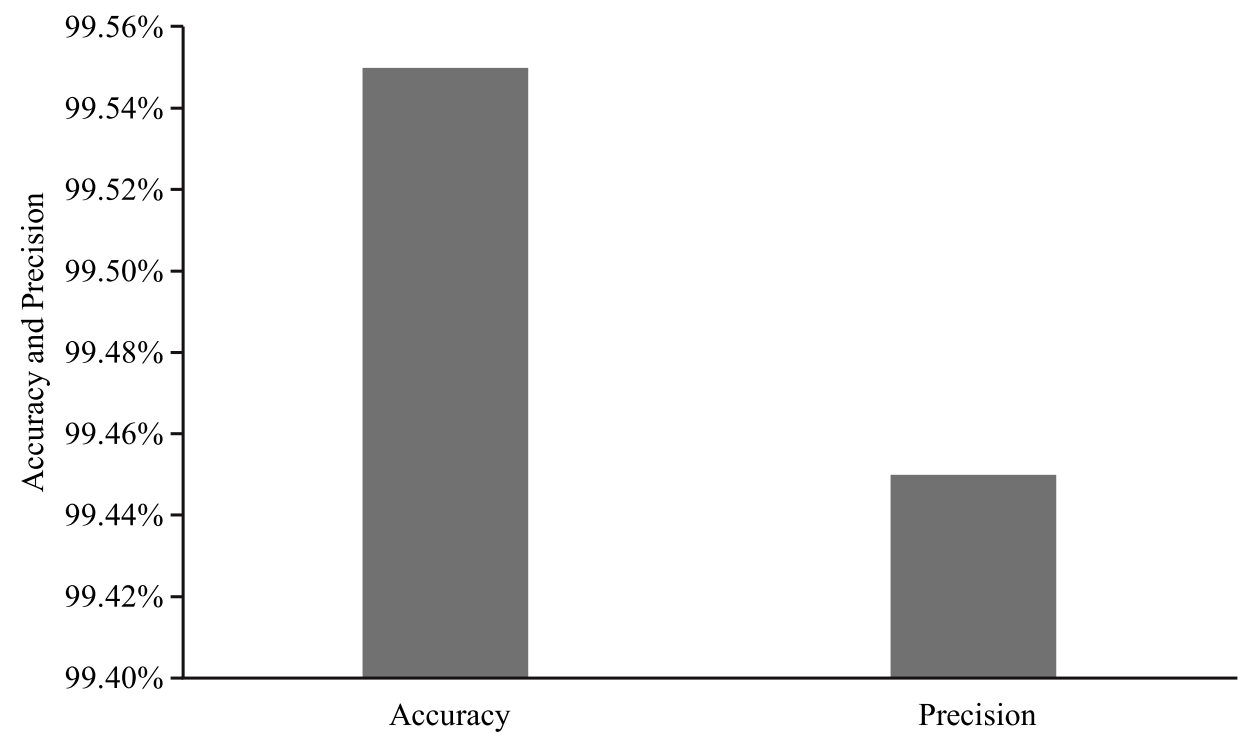

FIG. 10. COLUMN CHART OF ACCURACY AND PRECISION FOR CYLINDER

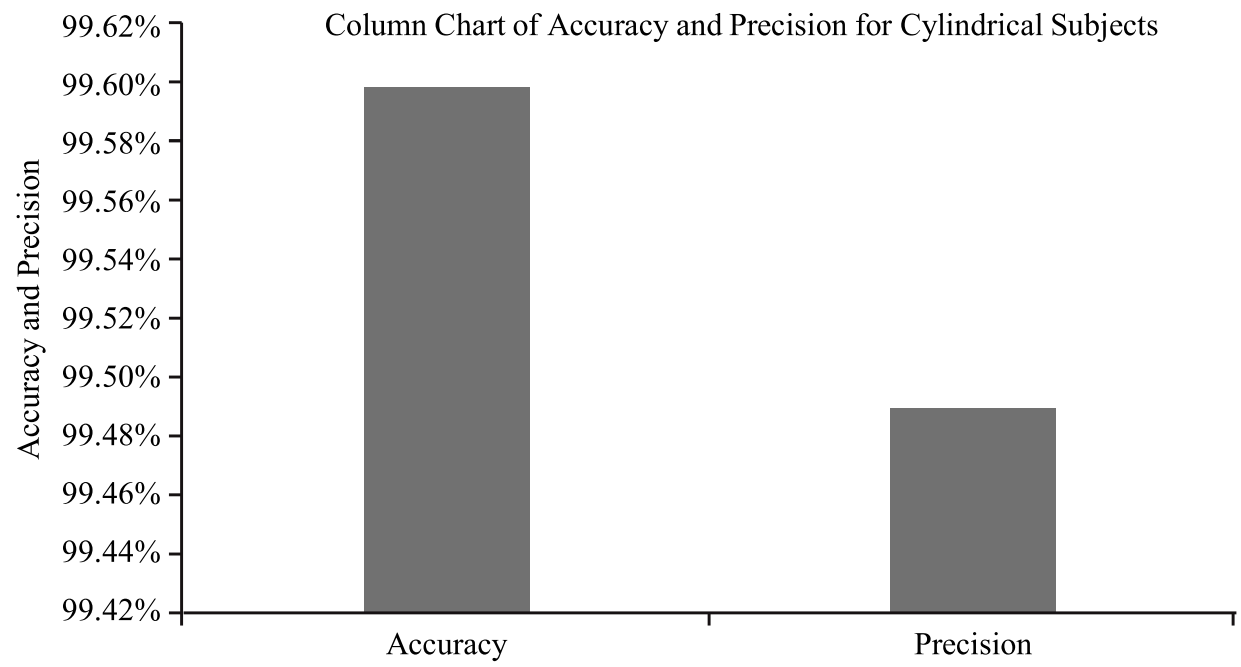

FIG. 11. ACCURACY AND PRECISION FOR CYLINDRICAL SUBJECTS 
and SE (Standard Error) was calculated by:

$$
S E=\frac{\sum e^{2}}{N}
$$

where

$$
e=y-\hat{y}
$$

where

$$
\hat{y}=a+b_{x / y} x
$$

where

$$
a=\bar{x}-b \bar{y}
$$

where

$$
\bar{x}=\frac{\sum x}{n}
$$

and

$$
\bar{y}=\frac{\sum y}{n}
$$

$D_{R}=\frac{\sum\left|x_{i}-R\right|}{N-1}$

$A=100\left[1-\frac{D_{R}}{D_{R}+\bar{x}}\right]$

$$
D=\frac{\sum\left|x_{i}-\bar{x}\right|}{N-1}
$$

$$
P=100\left[1-\frac{D}{D+\bar{x}}\right]
$$

\section{RESULTS AND DISCUSSION}

Regression lines:

$\mathrm{Y}=0.9327+0.993 \mathrm{x}$
The Equation (18) represents the relation between the radius of curvature for the objects,

Where $\mathrm{x}$ is the radius of curvature as measured by the physical measuring instruments and $y$ is the radius of curvature as measured by the rasterstereographic technique. This relation can be seen in Figs. 3-4.

Regression lines:

$\mathrm{Y}=1.0048+0.9683 \mathrm{x}$

The Equation (19) represents the relation between the radius of curvature for the subjects,

Where $\mathrm{x}$ is the radius of curvature as measured by the physical measuring instruments and $y$ is the radius of curvature as measured by the rasterstereographic technique. This relation can be seen in Figs. 3-4.

These regression lines between measured $(\mathrm{x})$ and calculated (y) established that the experimental setup of rasterstereography was calibrated.

Coefficient of Correlation and SE:

Coefficient of correlation for all cases is:

$1>\mathrm{CR}>0.999$

SE for all cases is,

$0.04 \geq \mathrm{SE} \geq 0.017$

These results indicate the perfect positive correlation for this mathematical model with allowable error 0.04 or in other words, this technique is validated.

Accuracy and Precision:

Accuracy: $99.60 \%$

Precision: $99.49 \%$

These results were relatively better than the other mathematical models of rasterstereography. This means that this technique is more reliable. 


\section{CONCLUSION}

The technique was calibrated through the regression line for objects and subjects and validated through the coefficient of correlation and standard error and it was found that it is inexpensive, reliable, reproducible, efficient, effective and accurate. The rasterstereography setup may be installed easily in hospitals to examine the body deformities of the children.

Follow up at regular intervals till the end of their growth periods shall ensure. This technique may also find application in sports performance analysis as well as developing identification systems.

\section{ABBREVIATIONS}

OHP Over Head Projector

$\mathrm{X} \quad$ Radius of curvature measured

s Periodic Spacing of the Plane Surface

d Periodic Spacing of Curved Surface

$\kappa_{1} \quad$ Horizontal Curvature

$\kappa_{2} \quad$ Vertical Curvature

Y Radius of curvature calculated

$\Sigma \quad$ Summation

CR Coefficient of Correlation

SE Standard Error

A Accuracy

$\mathrm{P} \quad$ Precision

R Reference Value

\section{ACKNOWLEDGEMENT}

Authors are thankful to MS Sajiha and Mr. Junaid Anwer, who helped in photography for this technique.

\section{REFERENCES}

[1] Frobin, W., and Hierholzer, E., "Rasterstereography: A Photogrammetric Method for Measurement of Body Surfaces", Photogrammetric Engineering, Volume 47, No. 6, pp. 1717-1724, 1981.

[2] Frobin , W., and Hierholzer, E., "Rasterstereography : Photogrammetric Method for Measurement of Body Surfaces", Journal of Biological Photogrammetric, Volume 5, No.1, pp. 7-11, 1983.

[3] Hierholzer, E., and Schier, F, "Rasterstereography in the Measurement and Postoperative Follow-Up of Anterior-Chest-Wall Deformities", Kinderchir, Volume 41, No.5, pp. 267-71, 1986.
Arffa, R.C., Warnicki, J.W., and Rehkopf, P.C., "Corneal Topography Using Rasterstereography", Refractive Corneal Surgical, Volume 5, No.1, pp. 414-27, 1989.

[5] Naufal, S.C., Hess, J.S., Friedlander, M.H., and Grand, N.S., "Rasterstereography-Based Classification of Normal Corneas", Journal of Cataract Refractive Surgical, Volume 23, No. 1, pp. 143-49, 1997.

[6] Hierholzer, E., "Calibration of a Video Rasterstereographic System", Photogrammetric Engineering, Volume 60, pp. 745-750, 1994.

[7] Drerup, B., and Hierhoher, E., "Back-Shape Analysis using Video Rasterstereography and 3DReconstruction of the Spinal Shape", Clinical Biomechanics, Volume 9, pp. 28-36, 1994.

[8] Zubairi, J.A., and Kamal, M.M., "Methodology for Spinal-Deformity Detection using Rasterstereography", Proceedings of IEEE International Conference on Intelligent Processing Systems, Volume 97, pp. 1528-1531, Beijing, China, 1997.

[9] Zubairi, J.A., "Applications of Computer-Aided Rasterstereography in Spinal-Deformity Detection", Image and Vision Computing, Volume 20, pp. 319-324, 2002 .

[10] Drerup, B., Ellger, B.M., Bentrup, F.M., and Hierholzer, E., "Functional Rasterslereographic Images: A New Method for Biomechanical Analysis of Skeletal Geometry", Orthopade Volume 30, No. 4, pp. 242-50, 2001 .

[11] Guarnieri, F.A., and Guarnieri, J.C., "Comparison of Placido-Based, Rasterstereography and Slit-Scan Corneal Topography Systems", Journal of Refract Surgical, Volume 18, No. 2,pp. 169-76, 2002.

[12] Hackenberg, L., Hierholzer, E., and Liljenqvist, U., "Accuracy of Rasterstereography Versus Radiography in Idiopathic Scoliosis after Anterior Correction and Fusion", Studies in Health Technology, Information, Volume 91, pp. 241-245, 2002.

[13] Hackenberg, L., Hierholzer, E., Potzl, W., Gotze, C., and Liljenqvist, U., "Rasterstereographic Back-Shape Analysis in Idiopathic Scoliosis after Anterior Correction and Fusion", Clinical Biomechanics, Volume 18, No. 1, pp. 1-8, 2003.

[14] Schroeder, J., Reer, R., and Braumann, K.M., "Video Rasterstereography Back Shape Reconstruction: Reliability Study for Sagittal, Frontal, and Transversal Plane Parameter", European Spine Journal, Volume 24, No. 2, pp. 262-269, February, 2015.

[15] Yoon, S.Y., Seul, K.Y., Da Gam, L., and Dae, S.P., "Reliability and Validity of Rasterstereography Measurement for Spinal Alignment in Healthy Subjects", Physical Therapy Rehabilitation Science, Volume 5, No.1, pp. 22-28, 2016.

[16] Anne, T.F., Alice, B.M., Sylviane, H., Pierre, L., Stephane, A., and Romain, D., "Validity and Reliability of Spine Rasterstereography in Patients with Adolescent Idiopathic Scoliosis", Spine, Volume 42, No. 2, pp. 98105, 2017. 